\title{
QUEM CONTA MINHA HISTÓRIA? \\ AS MUTILAÇÕES DO CÂNONE E A CONSTRUÇÃO DO OUTRO EM FOE, DE J. M. COETZEE
}

WHO TELLS MY HISTORY? THE MUTILATIONS OF THE CANON AND THE MAKING OF THE OTHER IN J. M. COETZEE'S FOE

Jivago Araújo Holanda Ribeiro
Gonçalve**
Sebastião Alves Teixeira
Lopes**

RESUMO: Tomando a narrativa literária como campo fecundo para revisitação de obras já canonizadas, Foe, escrito em 1986 por J. M. Coetzee, se inscreve em um amplo debate acerca da representatividade dos sujeitos em situaçoes subalternizadas e suas possibilidades de expressão, via texto literário, que se inicia a partir dos anos 1960 com o recrudescimento dos estudos pós-coloniais. A obra em questấo reconfigura as relaçoes entre personagens outrora representados $n$ tradição da literatura inglesa, a saber, o colonizador branco e o escravizado negro. O texto e uma releitura direta de $A$ Tempestade (1611), de William Shakespeare, e Robinson Crusoé (1719), de Daniel Defoe. Interessa pensar em que medida se efetua na obra uma reconfiguraçáo dos posicionamentos de tais personagens, visando elucidar sub-representaçáo à qual o sujeito negro, na condiçáo de sujelto escravizado, foi submetido. Assim, este trabalho busca responder aos questionamentos que a obra literaria suscita na ordem das possibilidades de fala do sujeito negro e da legitimidade de sua representaçáo constituição como o Outro do colonizador. Para isso, privilegiamos as relações que se estabelecem na obra entre o sujeito europeu, detento da fala e da possibilidade da escrita, e o sujeito subalternizado, privado de sua capacidade de fala.

PALAVRAS-CHAVE: Pós-colonialismo; Outro; Foe; Colonizado; Coetzee.
* jivago_ar@hotmail.com

Mestre, Universidade Federal do Piaul.

miguel@gmail.com

Doutor, Universidade Federal do Piau.

ABSTRACT: By understanding literary narratives as a promising field or the reassessment of works that have already been canonized, Foe, written in 1986, by J. M. Coetzee, is inserted in a broad debate over the representation of subjects in subalternized situations and their possibilities of expression, via literary text, that starts in the 1960s with the resurgence of post-colonial studies. The literary work here analyzed reconfigures the relations among characters previously represented in the tradition of English literature, namely, the white colonizer and the black enslaved man. Coetzee's text is a direct rereading of The Tempest (1611), by William Shakespeare, and Robinson Crusoe (1719), by Daniel Defoe. It is interesting to reflect to which extent, considering Coetzee's writing, the relation between these characters undergoes a reconfiguration of the aforementioned positionings and how that narrative strategy aims at highlighting the underrepresentation to which the black subject has been submitted. In this sense, our analytical effort intends to answer some questions that the literary work raises, concerning the black subject's possibilities of speech and the legitimacy of his representation and constitution as the colonizer's Other. In order to do so, we have prioritized the relations established in the narrative between the European subject, holder of the speech and the possibility of writing, and the subalternized subject, mutilated and deprived of his capacity of speaking.

KEYWORDS: Postcolonialism; Other; Foe; Colonized; Coetzee. 
1. BLASER. "Raça", ressentimento e racismo: transformações na África do Sul, p. 111-137.

\section{INTRODUÇÃO}

Propomos neste artigo uma interpretação do romance Foe (1986), do autor ganhador do prêmio Nobel de Litera tura do ano de 2003, John Maxwell Coetzee que, partindo de uma perspectiva pós-colonial, evidencia o posiciona mento do negro no processo de construção narrativa e que constrói um espaço de reinvindicação da voz desse sujeito silenciado pelo cânone ocidental. É interessante perceber a relevância do local de fala do autor para que se possa pensar em que medida sua escrita lida com uma questão de relevância social. Nascido e criado na África do Sul, Coetzee presenciou o desgaste estrutural provocado em seu país pelo apartheid, sendo este um sistema de segregação racial que por lá se iniciou em 1948, logo após a Segunda Guerra Mundial e perdurou até o momento das primeiras eleições democráticas de 1994 com a eleição de Nelson Mandela. Todavia, como demonstra Thomas Blasser, a complexidade da questão racial na África do Sul é a nterior ao apartheid e se prolonga após o término do regime. ${ }^{1}$ As configurações históricas que formaram o terreno de sustentação para a ascensão desse regime de segregação da tam do século XIX e remontam às disputas de terra entre colonos e africanos.

Um ponto de partida para pensar um possível reflexo imedia to dessa segregação é a distribuição e agrupa mento, planejados, da população através do espaço urbano, levando em consideração a diferenciação racial: "Ao longo das décadas, os planificadores da urbanização, agindo em consonância com as elites urbanas ("brancas"), projeta ram as cidades conforme suas necessidades e geografias, trabalhando na manutenção de fronteiras e na contenção dos contatos". ${ }^{2}$ Portanto, uma miríade de questões é colocada para a construção de uma nação pós-apartheid, como apontado por Neville Alexander, desde o entendimento do que seja uma política multicultural, até a natureza e as possibilidades de coesão social, passando pela consideração acerca das lideranças de classe. ${ }^{3}$

Não sendo o escopo deste trabalho uma apresentação da problemática racial na África do Sul nos termos de sua persistência na atualidade, nos permitimos pontuar a questão visto que a dinâmica de sua construção viabiliza um alinha mento enquanto pano de fundo cultural de onde surge a proposta narrativa de Coetzee em perspectiva pós- colonial. Desta maneira, Foe, na medida em que postula reflexões acerca da possibilidade de fala do negro, enseja o debate acerca das relações inter-raciais. A obra ta mbém situa, ainda, seu leitor frente a um violento processo de construção identitária do sujeito negro enquanto o Outro colonizado e destituído pelas práticas do colonizador de suas possibilidades de expressão.
EM TESE
BELO HORIZONTE
v. 23
N. 3
SET.-DEZ. 2017
GONÇALVES; LOPES. Mutilações do cânone e construção do Outro em Coetzee P. 85-99

2. BLASER. "Raça", ressentimento e (tesseñinentó do Sul, p. 118.

3. ALEXANDER. Cidadania, identidade racial e construção nacional na racial e construção nacionaln
África do Sul, p. 113-129. 
4. BONNICI. Introdução ao estudo das literaturas pós-coloniais, p. 19
Tal mérito advém da exposição das reminiscências de um processo de segregação social que, apesar de findado, persiste através do enraiza mento de suas consequências em relação ao debate acerca da segregação racial na África do Sul, seguindo o argumento de Thomas Bonnici, ao referir-se a Foe:

O romance avança na problemática proposta pelo romance original e discute o silêncio do colonizado, a possibilidade de fala após uma história de brutalidades cometidas pelos europeus, o relacionamento entre colonizador e o colonizado, as modalidades não-canônicas de fala e escrita, a manipulação da história pelo europeu e a subversão gentil (o conceito de 'sly civility', discutido por Bhabha) do subalterno. ${ }^{4}$

O núcleo duro da presente proposta é, portanto, a a nálise, partindo do texto, das práticas que efetiva m esse processo e o embate entre colonizador e seu outro em busca da voz e da fala deste último. O problema para o qual Coetzee volta seus esforços criativos é essencial para a apreensão da força narrativa de Foe: se quem conta a história é ta mbém quem tem seu ponto de vista lido e legitimado, e este alguém tem sido, historicamente, sempre o homem branco, e se a configuração de um cânone de determinada nacionalidade é composta majorita riamente pela visão que daí emana, é mister constatar a fragilidade da participação do sujeito negro nas criações narrativas, ou a incoerência da construção das personagens negras limitadas à categoria do Outro.

Tendo em vista essa problemática, o a utor de Foe fornece a perspectiva da disputa pela voz e o direito do questionamento por parte do sujeito negro e a sua possibilidade de fala. Assim, a questão inicial "quem conta minha história?" é a incorporação de uma corajosa interrupção num processo de silencia mento que é histórico, possibilitando, portanto, pensar não só o que pode a literatura, mas o que ela de fato deve e alcança, em termos de desestabilização de tais categorias como se encontram enraizados em textos canônicos.

Partimos do pressuposto de que o autor se debruça sobre o a to literário como possibilidade de revisão de obras canônicas e como campo convida tivo para a desestabilização das relações raciais como historica mente consolidadas no cânone inglês, a través dos dois principais intertextos com os quais a obra analisada entra em diálogo direto, sendo elas A Tempestade (1611), de William Shakespeare, e Robinson Crusoé (1719), de Daniel Defoe. Consideramos que J. M. Coetzee, a través de sua escrita metaficcional, procede à uma releitura do cânone com vistas à exploração de tópicos caros à temática pós-colonial. 


\section{A BUSCA PELA FALA DO NEGRO}

Não é desinteressante notar que, em Foe, é dada ao leitor a possibilidade de acompanhar, por meio de relatos registrados em diário, as desventuras de Susan Barton, uma mulher inglesa e branca, em busca de sua filha supostamente sequestrada e levada ao Brasil. Todavia, dado o insucesso de sua jornada e decidida pelo retorno à sua terra natal, Susan embarca em um navio que acaba por ser palco de um motim durante a viagem de retorno à Europa. Neste ponto inicial da construção narrativa o mar, o naufrágio a ilha quase inabitada configuram-se como os elementos recorrentes nos intertextos com os quais a obra dialoga, notadamente: A Tempestade e Robinson Crusoé

$\mathrm{Na}$ sequência, a vida de Susan é poupada pelos rebelados e ela é posta à deriva juntamente com o capitão do navio, donde se segue que o capitão não resiste às condições adver sas e morre. Susan é, então, carregada pelo mar a uma ilha e resgatada pelos dois únicos habitantes do local: Cruso, o senhor da ilha, aqui uma explícita referência ao protagonista de Robinson Crusoé, e Sexta-feira, seu ajudante/criado, um ex-escravo de quinze a nos de idade que foi mutilado pelo seu a ntigo dono, tendo sua língua sido cortada, impedindo-o, assim, de comunicar-se através da fala. Susan Barton transforma em sua missão de vida achar alguém que domine o ofício da escrita e que seja capaz de contar a sua história e a de Sexta-feira, retratando-os como sobreviventes de um naufrágio que viveram numa ilha deserta e dela foram, por fim, resgatados.

A língua, ou a ausência dela, é entendida como incapacidade de narrar a própria história. Essa compreensão permite-nos entrever a essência de sua motivação. Parece exemplar o episódio em que Susan propõe o questionamento: "A língua é como o coração, sob esse aspecto, não é? Só que não morremos quando uma faca perfura a língua. Nesse sentido, podemos dizer que a língua pertence ao mundo do jogo, enqua nto o coração pertence ao mundo da seriedade" ${ }^{5}$

Pensando os meios de resistência ao colonizador, ensejados pela própria ação colonizadora, encontra-se inserida no cerne do romance a discussão acerca da fala do sujeito colonizado, - representado via sujeito escravizado de pele negra, na figura da personagem Sexta-feira - e as possibilidades de expressão dessa fala. Coetzee lança mão de um artifício direto de representação da situação da fala do colonizado: Sexta-feira é um sujeito outrora escravizado que é mudo porque teve sua língua cortada por seu ex-dono. Partindo dessa configuração, Susan Barton compreende desde o começo que sua provável narrativa ganhará um caráter de verdadeira, verossímil, fidedigna em relação às experiências vividas, se for capaz de encontrar meios que 
possibilitem a Sexta-feira externar sua história: "Contar minha história e silenciar sobre a língua de Sexta-feira não é melhor que pôr à venda um livro com páginas deixadas em branco sem explicação".

É fundamental perceber que, diante da missão heroica de Susan, o que subjaz no percurso da narrativa é um processo de violência no qual a construção e constituição do Outro se dará sempre por vias terceiras, ou seja: aquilo que o leitor é capaz de aduzir da personagem é tão somente o rela to do colonizador que o destitui de sua própria voz e, por conseguinte, de sua possibilidade de narrar sua história. Essa atividade fica evidente no excerto seguinte, no qual Susan desenvolve uma espécie de monólogo inquisitivo em que Sexta-feira é a única plateia:

E depois há o mistério da sua submissão. Por que, durante todos aqueles anos sozinho com Cruso, você se submeteu ao domínio dele, quando podia facilmente tê-lo matado, ou cegado e feito dele o seu escravo por sua vez? Existe na condição de escravo algo que invade o coração e faz do escravo um escravo por toda a vida, assim como o cheiro de tinta impregna para sempre o professor?

Partindo desse questiona mento acerca de uma natureza do escravo que permita a sua subalternização, podemos retomar as formulações de Alfredo Bosi quanto à violência de todo o processo de colonizar o outro. O autor desenvolve uma análise semântica do termo colonização, cuja origem remonta ao verbo latino colo que por sua vez é a raiz de dois outros termos: cultura e culto. ${ }^{8}$ Para o autor, o que se impõe quando atenta mos à pluralidade semântica da raiz do verbo que dá origem ao termo colonização é fundamentalmente percebermos como este processo se instaura violentamente e se apropria da existência do colonizado em todas as suas dimensões temporais: passado, presente e futuro.

Em relação ao futuro, a cultura, entendida como "o conjunto das práticas, das técnicas, dos símbolos e dos valores que se devem transmitir às novas gerações para garantir a reprodução de um estado de coexistência social" é submetida às demandas do colonizador a través do processo formal de educação. Este é o eixo central da obra e da condição de colonizado em que se encontra Sexta-feira, a saber, o problema de sua língua e a impossibilidade de sua fala: uma vez destituído de sua capacidade de fala, o sujeito passa a ser constituído pelas práticas e discursos de poder do colonizador que o caracteriza como seu outro. Destarte, a definição do "outro" em contexto colonial representa, para Bill Ashcroft ${ }^{10}$, a marcação dos limites que definem o ser do colonizador:
8. BOSI. Dialética da colonização, p. 14

9. BOSI. Dialética da colonização, p. 16.

0. ASHCROFT. Postcolonial studies: the key concepts, p. 154-155.
EM TESE
BELO HORIZONTE
v. 23
N. 3
SET.-DEZ. 2017
GONÇALVES; LOPES. Mutilações do cânone e construção do Outro em Coetzee P. 85-99 
11. In general terms, the 'other' is anyone who is separate from one's self. The existence of others is crucial in defining what is normal and in locating one's own place in the world. The colonized subject is characterized as 'other' throug and cannbalism, as a means establishing the binary separtion of the colonizer and colonized and asserting the naturaizess and primacy of the colonizing culture and world view.

12. SPIVAK. Pode o subalterno falar?
Em termos gerais, o 'outro' é qualquer um que seja separado do ser de alguém. A existência de outros é crucial para a definição do que é normal e para a localização de um ser no mundo. O sujeito colonizado é caracterizado como 'outro' através de discursos como primitivismo e canibalismo, como meio de estabelecer a separação binária entre colonizado e colonizador e afirmar a naturalidade e primazia da cultura colonizador e sua visão de mundo. ${ }^{11}$ (Nossa tradução)

Aqui se inscreve a tese principal de Gayatri Spivak ${ }^{12} \mathrm{em}$ relação à própria constituição do outro enquanto sujeito interpelado por práticas de poder do colonizador com vistas a demarcar os limites constituintes daquele que é dominado. Delimitar o desejo do outro e formar esse outro a partir do discurso é uma prática de delimitação da diferença, portanto, se constitui como processo de construção identitá ria do colonizado ao passo que concomitantemente sublinha a constituição do colonizador. A natureza dessa demarcação identitária é explicitada na fala de Susan:

Quando fui ralhar com ele, encontrei-o girando devagar com a flauta nos lábios e os olhos fechados; ele não me deu nenhuma atenção, talvez nem tenha ouvido minhas palavras. Como é típico de um selvagem dominar um instrumento musica desconhecido - até onde é capaz sem a língua - e em seguida se contentar em tocar para sempre a mesma melodia! É uma forma de incuriosidade, não é? Uma forma de preguiça. Mas estou divagando. ${ }^{13}$

É latente na passagem acima a recorrente mentalidade colonizadora na classificação do Outro enqua nto selvagem. O que se segue é uma série de superinterpretações do ato de Sexta-feira que é, tão somente, em primeira análise, um a to banal, mas que pelo crivo do europeu constitui a própria prova da essência de um sujeito desprovido de qualquer capacidade cognoscível. Tal prática, a formação identitária através da construção discursiva, é maximizada no romance de Coetzee, visto que Sexta-feira é constantemente interpelado pela fala dos sujeitos que detêm sua tutela, como acabou de ser exposto.

Interessante ressaltar que, na perspectiva de Spivak, a esfera de abrangência dessa prática é ainda mais radical ao considerar o exercício intelectual-discursivo que busca homogeneizar o sujeito desejante das classes subalternas. A autora resgata as formulações de Michel Foucault, assim como de Gilles Deleuze e Felix Guatarri, os quais, através de termos como "proletariado", "classe trabalhadora", "divisão internacional do trabalho", não demonstra m abertura interpretativa para a heterogeneidade constitutiva dos sujeitos subalternizados; a autora enfatiza que "Por fora (mas não exa ta mente por completo) do circuito da divisão internacional do trabalho, há pessoas que não podemos

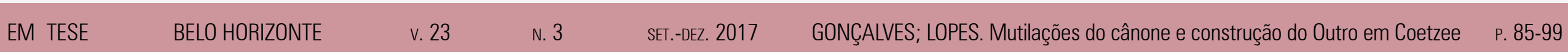


14. SPIVAK. Pode o subalterno falar?, p. 70.

15. POYNER. Coetzee and the paradox of postcolonial authorship, p. 93.

16. In Foe it is the silence of Friday's tongue that gradually overwhelms the narrative. The novel was penned at the height of apartheid oppression, in the years of the States of Emergency, beginning in 1985, so Friday's muteness readily associates itself with the silencing of South Africa's black peoples who not least were denied the rights of free citizens and a voice in matters of the state. compreender se nos isolarmos em nossa benevolência ao construir um Outro homogêneo [...]"e tal prática discursiva acabaria "se referindo apenas ao nosso próprio lugar no espaço do mesmo ou do Eu (Self)". ${ }^{14}$

Portanto, a configuração epistêmica do Outro europeu representado através de categorias homogeneizantes a partir do discurso intelectual de herança francesa, reforça a estrutura do argumento desenvolvido por Jane Poyner, em um estudo no qual desempenha uma extensa problematização da questão da autoria na obra de J. M. Coetzee. Sua proposta é de que o elemento dominante na narrativa em Foe (1986) é o silêncio ao qual Sexta-feira é relegado; segundo a autora, este silêncio é representativo da situação dos direitos individuais suprimidos na África do Su pós-apartheid: ${ }^{15}$

Em Foe é o silêncio da língua de Sexta-feira que gradualmente domina a na rra tiva. O romance foi escrito no auge da opressão advinda do apartheid, nos anos dos Estados de Emergência iniciando em 1985, desta forma a mudez de Sexta-feira associa-se imediatamente com o silenciamento dos povos negros da África do Sul aos quais foram negados os direitos de cidadãos livres e voz nas questões de estado. ${ }^{16}$ (Nossa tradução)

Por este prisma, numa análise inicial é necessário direcionar a discussão dessa diferença/oposição entre colonizador colonizado no romance rumo à sua herança racial, ou seja, seu aparecimento no romance vem na esteira de tensões raciais que são heranças coloniais e que reverberam no presente sul-africano.

Em princípio, tal oposição aparece a través da dicotomia civilizado/bárbaro, e a obra tem ao menos duas camadas. A primeira é explicitada na relação entre Susan e Cruso. Susan recusa os métodos de Cruso e seu modo de existência (destituído de a mbições civiliza tórias) na ilha. É sua intenção fazer com que Cruso adote elementos representativos de uma civilidade modelo: "Ele falava como se ferramentas fossem invenções bárbaras. No entanto, eu sabia que, se tivesse nadado a té a terra com um serrote amarrado ao tornozelo, ele o teria pegado e usado alegremente". Na visão de Susan, o trato da terra deve objetivar sua exploração por parte de seus habitantes, o que a faz desconsiderar qualquer outro método de subsistência: "Quando passava pelos terraços e via aquele homem, não mais jovem, labutando no calor do dia para erguer da terra uma grande terra ou pacientemente cortando o mato, achava aquilo um tipo idiota de agricultura" ${ }^{17}$

A segunda é a relação entre sr. Foe e Sexta-feira, que não se configura propriamente como uma relação em que se desenvolve um entrelace de subjetividades, mas especificamente as percepções de sr. Foe em relação a Sexta-feira, 
em que o primeiro não é capaz de enxergar no último nada além de uma tábula rasa, o colonizado olhado por seu outro, e inferiorizado a partir desse olhar: "pois enquanto ele for mudo podemos dizer a nós mesmos que seus desejos são desconhecidos para nós, e continuar a usá-lo como quisermos" ${ }^{18}$ É possível inferir que Sexta-feira é a fonte que alimentará suas histórias a partir dos estereótipos do selvagem africano.

A diferença entre o negro escravizado e o branco colonizador é dada a partir da não-compreensão dos modos de expressão de Sexta-feira, como atesta Susan depois de fracassar em sua missão de ensiná-lo a escrever:

Todos os meus esforços para conduzir Sexta-feira à fala, ou conduzir a fala a Sexta-feira, falharam, eu disse. Ele só se expressa em música e dança, que estão para a fala como gritos e berros para as palavras. Há momentos em que me pergunto se em sua vida pregressa ele teve o mais vago domínio de linguagem, se ele sabe que tipo de coisa é a linguagem. ${ }^{19}$

Não se deve aduzir daí que o autor trabalhou essas categorias a partir de lugares-comuns, que são justamente aqueles combatidos pela abordagem pós-colonialista. A chave de leitura que aqui propomos é: a narrativa reforçaria os estereótipos se trabalhasse essas categorias de maneiras fixas e fechadas em relação a qualquer questionamento qua nto à sua natureza imutável. O negro ca nibal. O europeu iluminado. A mulher subalterna. Todavia, não é através deste viés que a narrativa transita. Lançando mão do artifício metaficcional, o autor faz com que a busca incessante de Susan Barton sirva como motor que impulsiona a desestabilização dessas categorias, sugerindo o constante estranhamento por parte de Susan, o que, por conseguinte, instiga o leitor a acompanhá-la em sua caminhada de reavaliação destes posicionamentos.

Susan questiona reiterada mente o processo de construção de sua própria história, além de se revelar em constante angústia existencial por não ser capaz de suscitar em Sextafeira sua capacidade de fala, e por enxergar o silêncio de Sexta-feira como barreira a ser superada para que se possa enfim alcançar a essência de sua história pregressa, como ela aponta: "Nas cartas que o senhor não leu, eu disse, falei de minha convicção de que, se a história parece idiota, é apenas porque ela guarda silêncio muito teimosamente. A sombra que o senhor sente falta está ali: na perda da língua de Sexta-feira”. ${ }^{20}$

A fala que se configura como alvo da busca de Susan, e que outrora foi possuída por Sexta-feira, é a fala entendida como expressão autêntica: parte da composição do próprio sujeito. Ela advém da própria língua materna de Sextafeira, ou seu próprio método de comunicação oral. Também
EM TESE
BELO HORIZONTE
v. 23
N. 3
SET.-DEZ. 2017
GONÇALVES; LOPES. Mutilações do cânone e construção do Outro em Coetzee P. 85-99 
advém da maneira em que possivelmente se manifestava antes de sua mutilação - roubada qua ndo teve a língua a mputada. Portanto, há uma busca pela voz de Sexta-feira, e esta busca é perpassada por um sentimento de culpa visto que a voz do sujeito é sempre inalcançável, ou indesejável, e também objeto de uma disputa argumenta tiva entre Susan e sr. Foe.

\section{LÍNGUA, SILÊNCIO E RESISTÊNCIA}

Já problematizada no começo do romance, a ausência da língua de Sexta-feira é vista por Susan como mero percalço em relação à abolição do tédio na ilha em que habitava juntamente de Cruso:

O senhor fala como se a língua fosse uma das perdições da vida, como o dinheiro ou a varíola', eu disse. 'No entanto, não teria aliviado a sua solidão se Sexta-feira dominasse o inglês? O senhor e ele podiam ter experimentado, todos esses anos, os prazeres da conversação; o senhor poderia ter passado a ele algumas das bênçãos da civilização e feito dele um homem melhor. Que benefício existe uma vida de silêncio? ${ }^{21}$

Como é viável notar, a última pergunta deferida por Susan é reveladora do jogo de vozes implicado na ação colonizadora. A personagem supõe que Sexta-feira passaria por um processo de melhoramento cultural e moral a partir da assimilação da língua daquele que o colonizou, o seu outro imediato. Assume, ainda, que, sem a capacidade de comunicação a través da língua do colonizador, o colonizado está fadado ao silenciamento, portanto privado do suposto aprimora mento cultural e moral. Porém, como argumenta Jane Poyner, ${ }^{22}$ a busca por mecanismos de expressão que partam do colonizador já implica um silencia mento; dessa ma neira Sexta-feira é triplamente silenciado, como ressalta o crítico:

Triplamente silenciado (Sexta-feira) pois não somente é silenciado como mudo e silenciado pelo discurso colonial, ele também é mal interpretado por Cruso, Barton e Foe que, eles mesmos sujeitos ao discurso, falham em reconhecer sua resistência à mentalidade imperial. Ironicamente, portanto, ele é efetivamente silenciado por aqueles - primariamente Barton, mas ta mbém Foe - que se esforçam para lhe dar voz. ${ }^{23}$ (Nossa tradução)

Daí advém o caráter criativo de uma existência que não pode se materializar através da linguagem do colonizador. Sexta-feira se comunica, ou se expressa, a través de instâncias que fogem ao jugo da linguagem. O silencia mento opera em via dupla: resistência e criatividade. Isto é explicitado quando a mulher relembra sua volta à Inglaterra junto a Sexta-feira, e sua estadia na casa do próprio sr. Foe quando
22. POYNER. Coetzee and the paradox of postcolonial authorship, p. 102.

23. [...] triply silenced because not only is he silent as mute and silenced by colonial discourse, he is also misread by Cruso, Barton and Foe, who, themselves subject to discourse, fail to recognize his resistance to the imperial mindset. Ironically, therefore, he is effectively silenced by those primarily Barton but also Foe - who undertake to give him voice.
EM TESE
BELO HORIZONTE
v. 23
N. 3
SET.-DEZ. 2017
GONÇALVES; LOPES. Mutilações do cânone e construção do Outro em Coetzee P. 85-99 
este ainda se encontrava ausente. Susan lamenta da seguinte maneira:

Depois que Sexta-feira encontrou seus mantos e perucas e as tomou como sua vestimenta, passava dias inteiros girando, dançando, cantando à maneira dele. O que não contei foi que ao dançar ele não usava nada além dos mantos e da peruca. Quando parado, ficava coberto a té os tornozelos; mas, quando girava, os mantos se erguiam em volta dele, de tal forma que se poderia supor que o propósito da dança era mostrar a sua nudez por baixo. ${ }^{24}$

Há uma carência de percepção em relação à recusa de Sexta-feira de aderir aos métodos comunicativos, seja através da escrita ou da fala, de Susan e de sr. Foe. O que está em xeque aqui é a exclusão da perspectiva de criar meios para que o colonizado se expresse em sua própria língua permitindo-o uma construção de sua subjetividade que tenha origem em suas próprias percepções de mundo ou valores culturais, sendo essa ausência o silencia mento mais violento que poderia acometê-lo, visto que sua identidade se formará através do discurso que o interpela e que se origina essencialmente na fala do outro-colonizador.

Desta percepção sobre a construção da subjetividade do sujeito em condição subalterna, é mister retomar Homi Bhabha, em "Interrogando a Identidade", capítulo de sua obra O local da cultura, qua ndo este direciona atenção às fronteiras instáveis da formação das identidades do branco e do negro. Ao interrogar-se sobre a formação da identidade do negro, retomando a perspectiva psicanalítica de Frantz Fanon, e pensando em termos relacionais, ou seja, em que medida a identidade do negro, assim como a do homem branco, sofre a influência do outro na formação de sua psique, Bhabha consegue demonstrar que a "luta contra a opressão colonial não apenas muda a direção da história ocidental, mas também contesta a sua ideia historicista de tempo como um todo progressivo e ordenado". ${ }^{25}$

Isto implica pensar, a um só tempo, acerca da legitimidade da busca que se desenvolve no romance e da violência à qual se submete o sujeito privado pelo outro-inimigo - que é o próprio jogo de palavras no título do romance Foe - de sua livre expressão, posto que em escala a mpliada essa busca constitui-se como uma representação a mpla do próprio processo histórico de supressão das falas de sujeitos em estado de opressão, revelando assim que a história hegemônica e as narrativas que a sustentam sofrerão fissuras à medida que novos processos narrativos se constituam como instâncias de contestação, o que fica evidente quando Susan ressalta que o silêncio de Sexta-feira os impede de entrever sua verdade:

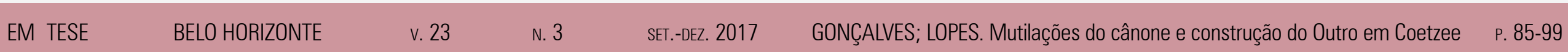


26. COETZEE. Foe, p. 109.

27. BHABHA. O local da cultura.
O senhor erra muito flagrantemente ao não distinguir entre meus silêncios e o silêncio de Sexta-feira. Sexta-feira não tem nenhum domínio sobre palavras e, portanto, nenhuma defesa contra ser remodelado dia a dia em conformidade com os desejos de outros. Digo que ele é um canibal e ele se torna um canibal; digo que ele é um lavador de roupas e ele se torna um lavador de roupas. Qual é a verdade de Sexta-feira. ${ }^{26}$

Tendo em vista que Sexta-feira não detém meios para lutar contra seu opressor em qualquer nível de confronto que não o físico, acreditamos que a perspectiva coetzeeana ao colocar em disputa a legitimidade de uma narrativa canônica, que assim se fez à custa do silenciamento das minorias, já é um demonstrativo do rompimento, em consonância com o proposto por Homi Bhabha, ${ }^{27}$ do tempo histórico linear. $\mathrm{O}$ ideal de progresso e civilização que avança linearmente conforme a passagem do tempo, imaginado por Susan, não se efetiva perante as rupturas provocadas pelas interpolações das minorias. Dessa maneira, a presença das marcas do colonizador na constituição do negro é perceptível no romance a partir da violência característica de sr. Foe com relação a Sexta-feira. De fato, trata-se de uma violência simbólica, quando se leva em consideração a proposta de sr. Foe em ensinar a Sexta-feira o alfabeto da língua inglesa para que esse possa contar sua história a partir dela.
Para além da comunicação através da língua, que na perspectiva de Susan atenderia apenas à necessidade de comunicar comandos básicos, o silêncio imposto a Sextafeira é carregado de um simbolismo ainda mais agudo: "Em algum lugar nos recessos ma is profundos daquelas pupilas pretas havia uma faísca de zombaria? Eu não conseguia ver Mas se havia, não seria uma faísca africana, opaca aos meus olhos ingleses?". ${ }^{28}$ Este silêncio sublinha a impossibilidade de comunicação entre colonizador e colonizado ao nível da cultura e do choque entre duas formas distintas de existência (Coetzee retomará essa incapacidade comunicativa em Disgrace, obra de 1999).

É preciso, em maior grau de importância, aludir ao jogo de poder que subjaz a prática do colonizador ao privar o colonizado de sua fala, o que fica evidente quando sr. Foe declara: "Pois enquanto ele for mudo podemos dizer a nós mesmos que seus desejos são desconhecidos para nós, e continuar a usá-lo como quisermos” ${ }^{29} \mathrm{O}$ domínio da fala pelo colonizador é uma prática de controle do colonizado por natureza, visto que o priva de qualquer possibilidade de expressão. Percebendo de maneira acurada toda essa dinâmica, Susan se dá conta da impossibilidade de uma História que não cede espaço para que o subalterno fale por si. É o que sobressai da seguinte passagem:
28. COETZEE. Foe, p. 131.

29. COETZEE. Foe, p. 133.

EM TESE

BELO HORIZONTE

v. 23

N. 3

SET.-DEZ. 2017

GONÇALVES; LOPES. Mutilações do cânone e construção do Outro em Coetzee P. 85-99 
30. COETZEE. Foe, p. 62

31. POYNER. Coetzee and the paradox of postcolonial authorship, p. 100.
Depois, há a questão da língua de Sexta-feira. Na ilha, aceitei que nunca saberia como Sexta-feira perdeu a língua, assim como aceitei que nunca saberia como os macacos atravessam o mar. Mas o que podemos aceitar na vida não podemos aceitar na história. Contar minha história e silenciar sobre a língua de Sexta-feira não é melhor que pôr à venda um livro com páginas deixadas em branco sem explicação. No entanto, a única língua que pode contar o segredo de Sexta-feira é a que ele perdeu! ${ }^{30}$

O aprendizado da língua do colonizador já faz parte de um dos intertextos com os quais Foe está diretamente posto em diálogo: a peça A Tempestade, de 1619 de William Shakespeare. Na peça a situação do colonizado é ta mbém representada pelo discurso do colonizador e reforçado pela habilidade do primeiro em se comunicar pela língua do seu senhor; a língua do colonizador serve mais ao propósito da a tividade colonizadora do que à preocupação efetiva de dar voz ao colonizado.

No entanto, ao contrário de Caliban, que faz uso da língua para xingar seu senhor, a intenção dos donos da fala em Foe parece ser a materialização do desejo de Sexta-feira. É o que aponta Jane Poyner ${ }^{31}$ quando mostra que Susan é incapaz de reconhecer sua falha no âmbito de seu esforço de fazer Sexta-feira reproduzir uma língua que não é sua:
Barton está errada em duas instâncias: em primeiro lugar, ela intenciona impor a língua do colonizador a Sexta-feira. O Caliban de William Shakespeare em A Tempestade, um dos intertextos de Foe, é bem ciente dos mecanismos opressores que estão em funciona mento em tal ma nobra, vez que a língua serve apenas para "iluminar" o próprio colonizador em seu processo de escravização. Em seguida, como o romance revela posteriormente, Sexta-feira ativamente escolhe o silêncio quando se recusa a ser ensinado por Barton a ler e escrever. 32 (Nossa tradução)

Ainda assim, como enfatizado por Sam Durrant, a través de um jogo de palavras na língua inglesa, a "mut(e)ilation", a mutilação sofrida por Sexta-feira acaba por tornar-se o centro da narrativa que Susan busca contar, e o silenciamento do sujeito outrora escravizado é que agrega à narrativa todo o peso do luto representa tivo da própria história recente da África do Sul em relação as tensões sociorraciais. Destarte, existem dois pontos essenciais que são destacados por Sam Durrant ${ }^{33}$, na outridade da ação de Susan em relação a Sexta-feira: em um primeiro momento ao intitular-se guardiã do sujeito, ela deliberadamente assume o papel de seu ex-senhor e toma como sua missão o controle das possibilidades de expressão cultural de Sexta-feira; em um segundo momento, há o desenrolar de uma leitura do desejo de Sexta-feira que, ao contrário da obra canônica,
32. Barton is wrong on two counts: firstly, she intends imposing the language of the colonizer on Friday. William Shakespeare's Caliban in The Tempest, one of Foe's intertexts, is all too aware of the oppressive mechanisms at work in such a manoeuvre because language serves only to "enlighte hen on his enslavement. [...] Friday actively chooses silence when he refuses to be tutored reaning refuriting by

33. DURRANT. Postcolonial narrative and the working of mourning 2004.

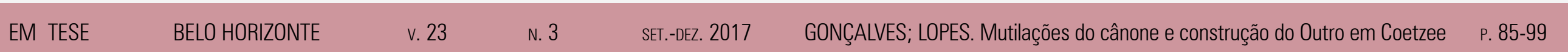


34. ATTRIDGE. The silence of the canon. In: Literature in the even

Reading p. 65-90.

35. COETZEE. Foe, p. 142. não é voltado para a necessidade de servir, mas sim à vontade de ser livre.

Dessa maneira, como já bem destacado por Derek Attridge, ${ }^{34}$ torna-se difícil a tarefa de precisar a voz do narrador na última cena descrita no romance. Pela simbologia envolvida, não se sabe se quem narra é o próprio sr. Foe, Daniel Defoe, Susan Barton, Coetzee ou o próprio leitor emprestando sua voz à reivindicação de Sexta-feira. Esta constatação deve-se ao fato de que a descrição da cena opera uma convergência de todas essas vozes que estão imbricadas no processo das conquistas culturais que se fizeram ao longo dos séculos e que são debitá rias da violência perante o Outro colonizado. Assim se lê no excerto:

Sua boca se abre. De dentro dele vem um lento jorro, sem fôlego, sem interrupção. Ele flui através de seu corpo e sobre mim atravessa a cabine, atravessa o navio naufragado; banhando os rochedos e as praias da ilha, corre para o norte e para o sul até os confins da Terra. Suave e frio, escuro e sem fim, ele bate contra minhas pálpebras, contra a pele de meu rosto. ${ }^{35}$

Portanto, a vívida imagem do "jorro" que, se desvencilhando da necessidade da voz, parte do corpo, é a representação final de um amálgama que se forma a partir da confluência de diversas instâncias, a saber: a violência cultural, a subalternidade a que o sujeito é relegado enqua nto Outro, sua impossibilidade de narrar-se, seu deslocamento espacial, o empobrecimento de seu desejo. Seu alcance é longínquo e proporcional à dívida a ser cobrada que se façam ouvir aqueles cujas línguas foram mutiladas, $e$ que de norte a sul o eco do corpo desca racterizado represente a fissura necessária rumo a reivindicação da possibilidade de uma autorrepresentação.

\section{CONSIDERAÇÕES FINAIS}

Em suma, pode-se perceber uma atitude de resistência de Sexta-feira ao nível da fala. Há uma constante e forçosa a titude dos colonizadores em fazer com que Sexta-feira aprenda a língua inglesa, mesmo que este não demonstre nenhum interesse em fazê-lo. Pressupor a inconsciência da atitude de Sexta-feira seria rebaixá-lo à categoria do bárbaro que não adotou completamente a episteme do civilizado; longe disso, e tão próximo qua nto o próprio texto nos permite chegar da consciência de Sexta-feira, optamos por enxergar seu ato como um mecanismo revestido por um caráter de insubordinação.

Seria através da nova língua aprendida que a adoção da episteme do colonizador pelo colonizado se efetivaria; portanto, o silêncio a ele imposto através da mutilação serviu como o último refúgio contra a concretização da ação totalizante do colonizador, além de converter-se em enigma
EM TESE
BELO HORIZONTE
v. 23
N. 3
SET.-DEZ. 2017
GONÇALVES; LOPES. Mutilações do cânone e construção do Outro em Coetzee p. 85-99 
indecifrável perante a cultura eurocêntrica. É aberta, portanto, a perspectiva de uma existência para além da comunicação através da língua e da sujeição colonizadora; há em uma esfera ampla a dimensão da criatividade, da invenção. Outros modos de expressão pela via da materialidade do corpo, tais como a dança, os gestos e os sons emitidos pelo resquício da língua amputada, se transfiguram em novos modos de viver.

Além disso, Coetzee retoma uma narrativa canonizada através da criação metaficcional com o objetivo de reconfigurar a experiência da relação entre colonizador e colonizado. Não se trata de negligenciar o passado e suas consequências, ou ainda de abandonar obras literárias que constituem marcos nos desenvolvimentos de literaturas nacionais, mas sim retomá-las com vistas à problematização de pressupostos antes negligenciados. Dentre essas temáticas, temos a possibilidade de fala do escravizado e as consequências trazidas a este via aprendizado da língua do colonizador, bem como a violência inerente a todo o processo de dominação do colonizado.

Por fim, Foe é uma narrativa representante de uma postura crítica pós-colonial e demonstrativa da relevância da construção metaficcional, bem como de suas possibilidades, em relação à contemplação de temas caros a esta postura.
No recorte aqui proposto, é viável perceber a problematização da construção subjetiva do sujeito colonizado que é a todo momento interpelado pela ação de seu(s) outro(s) imediato(s), a saber, o homem branco, europeu, que, por meio da escrita, visa à legitimação de sua própria visão de mundo. A força maior da construção narrativa do romance parece, portanto, ser a capacidade de Coetzee de conduzir a percepção do leitor em relação à potência do a to do colonizado ao transfigurar o seu silenciamento em a to de resistência, a via pela qual o projeto do colonizador não será capaz de se efetivar enquanto um projeto de dominação do Outro colonizado.

\section{REFERÊNCIAS}

ALEXANDER, Neville. Cidadania, identidade racial e construção nacional na África do Sul. Tempo social, São Paulo, v. 18, n. 2, p. 113-129, 2006

ASHCROFT, Bill. Postcolonial studies: the key concepts. New York: Taylor and Francis Press, 2007.

ATTRIDGE, Derek. The silence of the canon. In: Literature in the event: J. M. Coetzee and the ethics of reading. Chicago: University of Chicago Press, 2004. p. 65-90.

BHABHA, Homi K. Interrogando a identidade: Frantz Fanon e a prerrogativa pós-colonial. In: O local da cultura. Belo Horizonte: Editora UFMG, 1998. p. 70-104 
BLASER, Thomas. "Raça", ressentimento e racismo:

transformações na África do Sul. In: Cadernos Pagu, Campinas,

n. 35, p. 111-137, 2010

BONNICl, Thomas. Introdução ao estudo das literaturas pós-

coloniais. In: Mimesis, Bauru, v. 19, n. 1, p. 07-23, 1998.

BOSI, Alfredo. Dialética da colonização. São Paulo: Companhia das letras, 1992

COETZEE, John Maxwell Foe. Tradução de José Rubens Siqueira. São Paulo: Companhia das Letras, 2016.

DURRANT, Sam. Postcolonial narrative and the working of mourning. State University of New York Press, 2004.

POYNER, Jane. J. M. Coetzee and the paradox of postcolonial authorship. Burlington: Ashgate, 2009.

SPIVAK, Gayatri. Pode o subalterno falar? Belo Horizonte: Editora UFMG, 2010.

Submetido: 28/03/2018

Aceito: 22/05/2018 